\title{
CONTEMPORANEOUS TRANSFORMATION OF PORTABLE SHELTERS IN THE FORM OF TENTS IN RAJASTHAN
}

\author{
ANUPAM JAIN $^{1}$ \& DIVYA HIRAN ${ }^{2}$ \\ ${ }^{1}$ Researcher, Faculty of Fashion Technology, PACIFIC University Udaipur, Rajasthan, India \\ ${ }^{2}$ Associate Professor, Govt. M.G. College, Udaipur, Rajasthan, India
}

\begin{abstract}
Tents have been fulfilling shelter needs, since time immemorial. Tent was an intrinsic part of the livelihood of nomadic tribes. Being a multi-faceted product, it can be transformed to suit the needs of its user. From housing royalty, especially of the Mughal era on their hunting or pilgrimage expeditions, to providing temporary shelters to the soldiers in the military, tent has exhibited immense flexibility and adaptability, which has enabled it to survive and flourish as a product.

As time progressed, tent was subjected to various changes and innovations. The opulent and regal aesthetics were gradually replaced with minimalistic British aesthetics. With the advent of modern technology, further innovation in its form and function were witnessed. This study aims at tracing the history of a tent as temporary shelter in Rajasthan, India, studying its contemporary uses and various types and further delving into the material and processes required to build it.
\end{abstract}

KEYWORDS: Tent, Temporary Shelters \& Rajasthan

Received: Jul 28, 2017; Accepted: Aug 18, 2017; Published: Aug 29, 2017; Paper Id.: IJTFTOCT20171

\section{INTRODUCTION}

Tents have served as living shelters, for nomadic tribes for centuries, including soldiers at war. Along with that, they have also been integral in fulfilling the housing requirements during outdoor leisure activities like hunting and pilgrimages. As there is no direct and sufficient literature, available on the history of tents in India, the researcher has to depend on the primary research on available indirect visual references, such as, a few traditional miniature and wall paintings, frescos and fading murals, those still exists in some forts and palaces of Rajasthan. A few earlier literary references of tents in India are also mentioned in Ayodhya Kande - in Prose, Sarga 80 of Ramayana by Valmiki, Mahabharata and in Vedic period as well. Hence, this study is mainly based on the primary data collection made through site visits, photo and visual documentation and its analysis (Valmiki Ramayan, 2003). Hunting was a popular activity, among the rulers of various Indian kingdoms and tents were the best option to rest and stay in the forests. The queens used to travel to pilgrimage centres and once again, tents were the best solution for their accommodation. The royal tents were well equipped with luxurious facilities, in order to provide comfort and security in all seasons. These tents were made of various natural materials such as cotton, wool and silk. Wool was derived from camel, goat and sheep hair and silk was derived from silkworms. Bamboo was also used as an important material, in these tents (Bhati, 2007). Today, synthetic materials like nylon, polyester and acrylic are also available as alternative options, for natural materials. Over the last few centuries, especially since the advent of textile fabric, tents have been subjected to innumerable and innovative changes in order to cater to 
the various needs of the user. From the unpretentious, rarely recorded, single pole covered with a large single fabric, that may be held in place, by weights or tied to pegs; to extremely opulent and luxurious tents of the royal and the rich, that indulged their every fantasy, and flaunted their power, status and self esteems, the tent has exhibited great flexibility and adaptability. Consequently, the fact that the design of a tent could be worked and reworked, to suit any requirement, marked it as a product with a significant capacity for customised and mass production. Each estate and region, especially of the Mughal and Rajputana kingdoms, used to have khemekakarkhanaa tent manufacturing workshop, and workshops for other equipment such as, fans, mattresses, durries, carpets, bed sheets, pillows etc. dealing with silk, woollen and cotton materials. The khemekakarkhana used to operate through large-scale staff strength, at different levels, that were experts in installing these tents. Separate workers used to maintain the house keeping and day-to-day requirements (Bhati, 2007). As observed thought primary investigations, even in present times, tents are still the solution for temporary shelter in the armed forces. Makeshift tents are used to house temples, mosques and churches as per the religious beliefs of soldiers; they accommodate hospitals, armouries, granaries, mobile repair units, hangers and garages, among other shelters. Tents are also very popular as temporary shelters, during outdoor shooting schedules of T.V. serials and movies. In fact, popular Indian T.V. serials like the Mahabharata, Ramayana, Tipu Sultan, Akbar and Chanakya, have depiction of tented encampments, which impel us to consider the possibility of this type of accommodation, in the ancient Indian subcontinent. The state of Rajasthan in India is a favourite location for many filmmakers. These pictures give further impetuous to tourism, in Rajasthan. The history of Rajasthan has given it a distinctly unique and vibrant cultural heritage. Different areas of Rajasthan have different topographical, seasonal and cultural identities. In some ways, traces of this complex cultural evolution find a reflection, in the tents of Rajasthan.

\section{Tradition and Continuity in Usage of Tents}

Indian history and architecture represents that, during their administrative interactions with Mughals, the Indian kings were greatly impressed and influenced by the systematic and traditionally hierarchical, luxurious layouts of the Mughal tents. These kings incorporated the discipline, planning and grandeur of the Mughal lifestyle, to their own principalities. Gradually, tents began to be utilised in various areas of civil life such as marriages, religious ceremonies, socio-cultural gatherings, hunting etc. This development, later gave rise to the production of tents in factories and workshops, for the entertainment industry. Apart from producing new tents, these workshops also catered to the reuse and repair of used tents. The concept of hiring tents instead of owning them gained popularity. A tent making industry came into being. Many factories produced tents for administrative and common use. Some workshops specialised in making of tents for the royal houses (Bhati, 2007). Kheme ka kuan in Jodhpur, is one such place where tent factories and workshops were established. Typically, tents made in this area used block printing in black ink, for surface enhancement of the tents. There was no limit to the adornment techniques and embellishments, when it came to the surface ornamentation of fabric to be used in making tents, for the royalty. Intricate gold and silver embroideries were used with precious stones on silk and velvet, to line the interiors of these tents (Bhati, 2007). The researcher during one of his field trips to Mehrangadh fort at Jodhpur in Rajasthan, witnessed an exquisite collection of antique tent pieces in its archive section, which is stored there as part of the national heritage, even today. Laldera, an exclusive historical tent presently with the royal family of Jodhpur, is a beautiful memory of the tents in the Mughal era. The culture of highly evolved, beautifully crafted and customized tents continued in India, due to the patronage and persistence of people like His Highness, the present Maharaja of Jodhpur, and Maharaja Gaj Singh. He initiated the tent making company, Royal Jodhpur Tents, which offers high-end 
exclusive tents for tourists. In recent years the Maharaja of Jodhpur erected whole cities of exotic tented structures, to entertain hundreds of wedding guests and guests of cultural events, offering them the most luxurious of hospitalities. In these encampments, he recreated and retained the splendour of the erstwhile Royal Camps (Jodhana Heritage Resorts, 2012).

\section{Paradigm Shift in the Culture and Function of Tents}

In India, the ostentatious opulence of the regal tents persisted well into the Colonial period. The Europeans brought with them a cultural heritage steeped in Industrialisation and minimalism. While the intricately handmade products of India were greatly appreciated and prized in the European markets, the Indians themselves appreciated the highly sophisticated tastes of the Europeans. This resulted in another leap in the development of tents. Significantly, the tents were modified and put to a wider range of uses, from luxury to functionality to basic utility. In the foreground of Figure No.1 are seen cattle carts covered with tents. These mobile tents exemplify, both, the regional variation and adaptation to particular needs that the tent is capable of, i.e. from fixed tents on ground to mobile-tented shelters on carts. Another major change in the use of tents came at the end of the Colonial period in India during 1947. The border states of India that were partitioned into Indian and Pakistani territories bore the brunt of refugee exodus from Pakistan and India. Refugee camps needed to be set-up overnight. Figure No.2 captures the essence of those traumatic times and the use of tented accommodation as bare necessity to provide temporary shelter to displaced population.

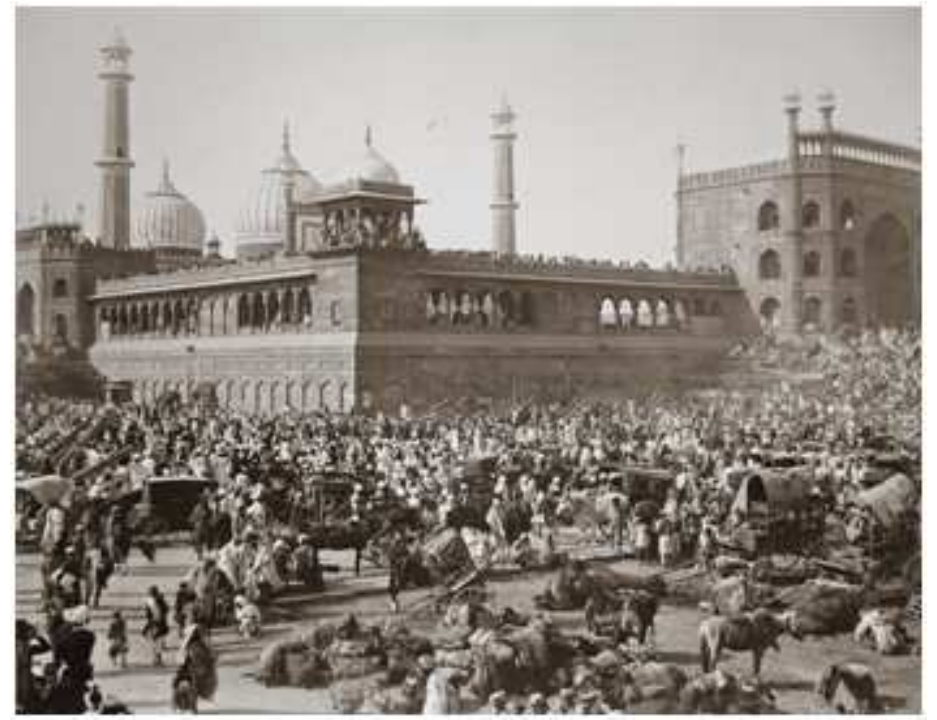

Figure 1: Perhaps the Most Perfectly-Proportioned of the Mughal Mosques, the Jama Masjid was the Centre-Point of Shahjahanbad. Its Surrounding Steps on three Sides Were Animated by Story-Tellers and Performers, and Commanded a Wonderful View of Lanes and Neighbourhoods (IGNCA and INTAC, 2010, p. 28) 


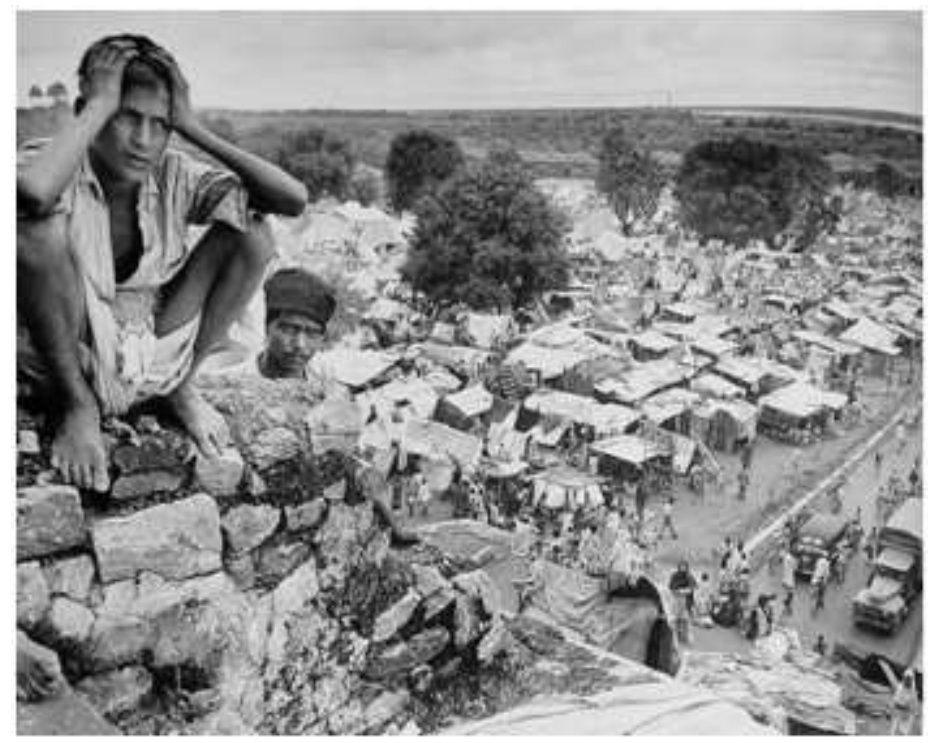

Figure 2: Independence in 1947 was Accompanied by Partition, and Delhi Changed irrevocably - it lost many People in the Communal riots, and Thousands of Families from the Provinces that made Up the New State of Pakistan Arrived in the City Desperately in Need of Shelter (IGNCA and INTAC, 2010, p. 104)

Another reference during the same time period of approximately 1940s visible in Figure No.3, is a scene of a market place, capturing the canvas awnings, canopies and bamboo chicks over window panels, being used above the shops, for creating a cool and exclusive environment for attracting interested buyers, including those from among the tourists.

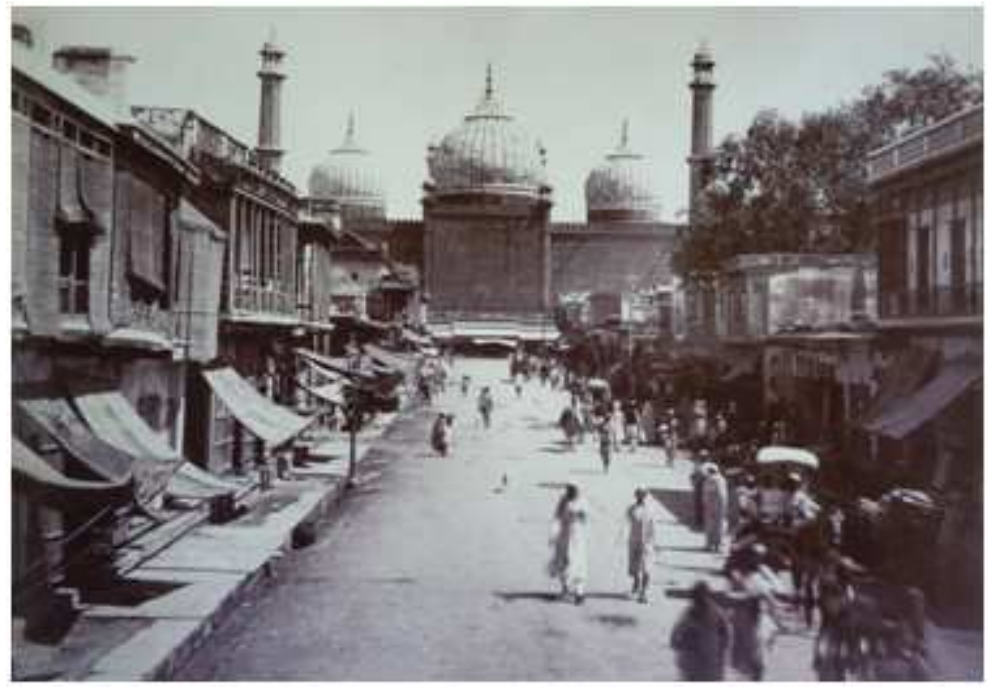

Figure 3: Scene of Chauri Bazar near Jama Masjid (IGNCA and INTAC, 2010, p. 81)

India, after the independence in 1947, emerged as a large democratic and independent state, with a mobile population curious to explore its' own country. Over the years, there may be a possible link between the marked increase in domestic tourism within the country and the visibility of tented encampments, adapted for leisurely pursuits. An influx of overseas tourism, eager to experience the mysticism and exotic grandeur of India, was not far behind. The contemporary urban population looks forward to learning about and, if possible, experiencing the cultural heritage of places visited. The urban tourist uses his leisure to interact with nature and connect with his primal being, to de-stress and relax. When members of the civil society and even the defence and administrative societies take a break from their hectic work 
schedules, they look forward to having time to 'stand and stare' at natures miraculous beauty and mankind's ingenuity. Other than leisure and utility, tents always remained as the integral part of defence forces. Even though the profile of war, and consequently the defence forces, has been completely changed by scientific and technological advancements, its association with tents continues. The material and technology used for fabrication and erecting of a tent for military purposes have only been modified, to suit the needs of military camps today. Used for hangers, transmitter colonies, hospitals and nursing dormitories; as store houses for arms, ammunition and food supplies; during mock drills and exercises; on ships and in submarines; by paratroopers, guerrilla warriors and deep sea divers, the list of use by the defence forces is unending. Simply, put the tent is a 'must have' in a soldier's and a country's survival kit. This section highlights the changes and indigenous adaptations, made to accommodate the shift in the culture and function of tents.

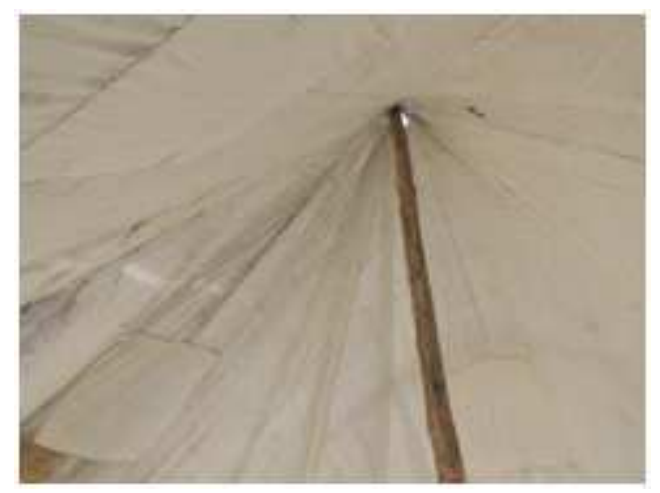

a.

Figure 4a: A Tent Roof Detailing, with a Central Pole and in (Researcher's own)

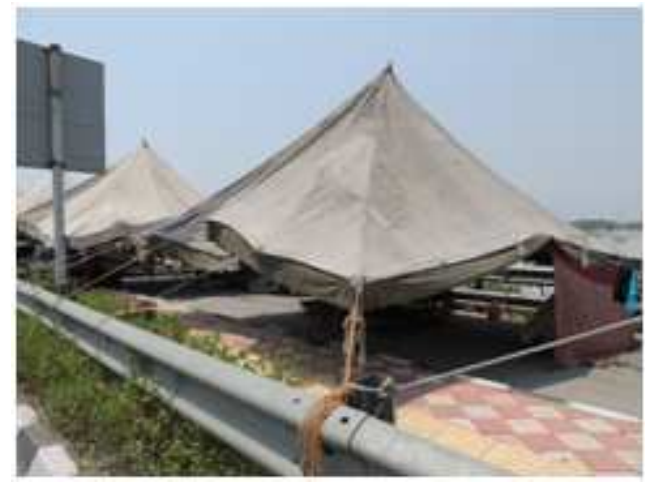

b.

Figure 4b: A Tent with Central Pole Tied with Ropes from Corners 


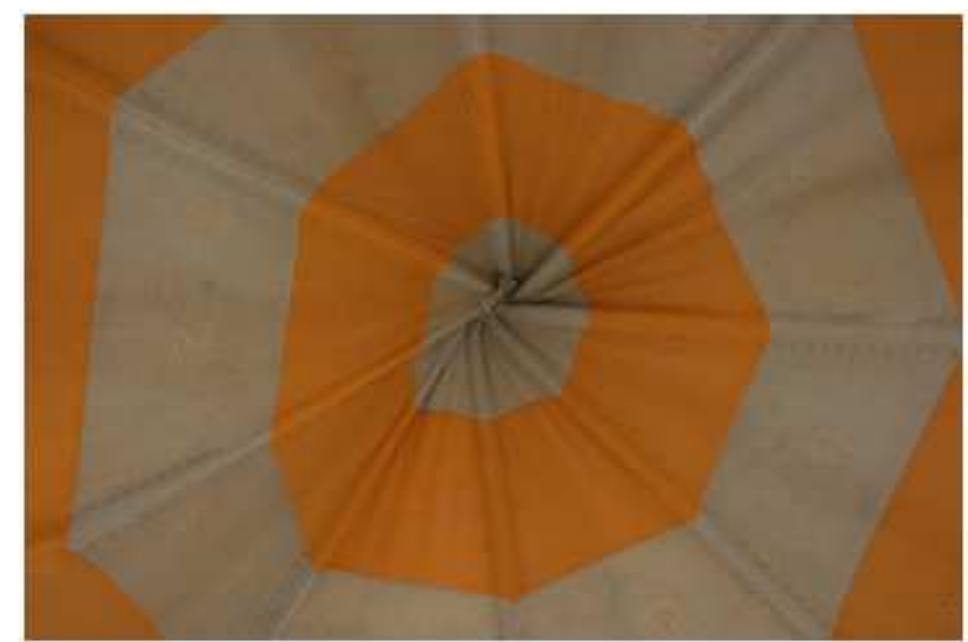

Figure 5A: Tent Roof Detailing, without a Central Pole (Researcher's Own)

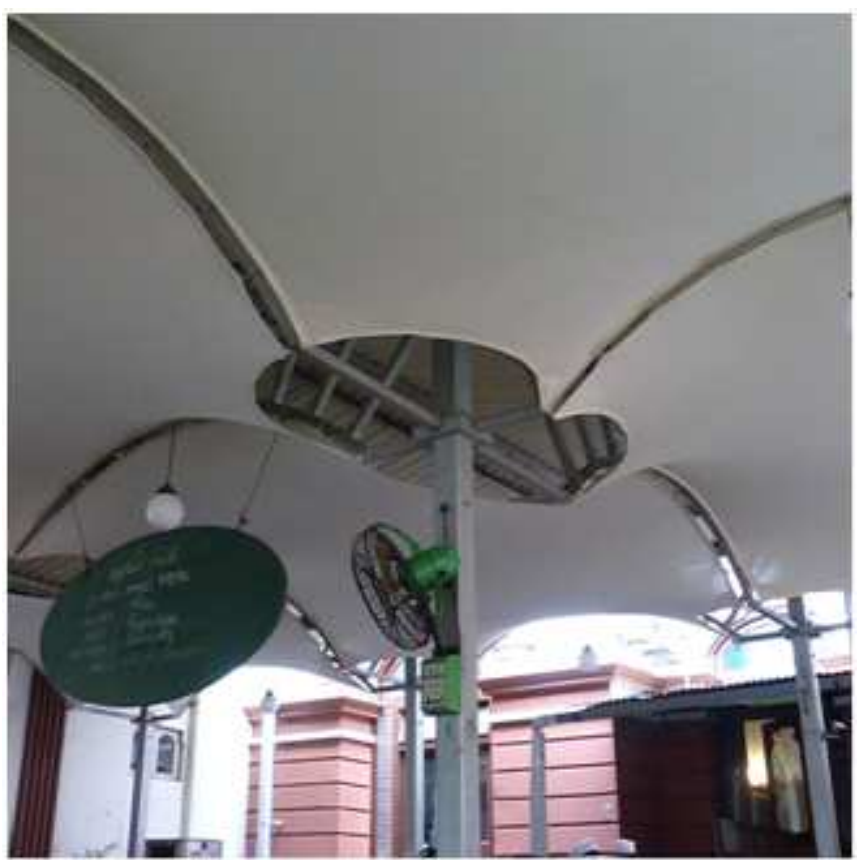

Figure 6: Food Court Roof, M.G. Agashiye, Ahmedabad (Researcher's Own) 


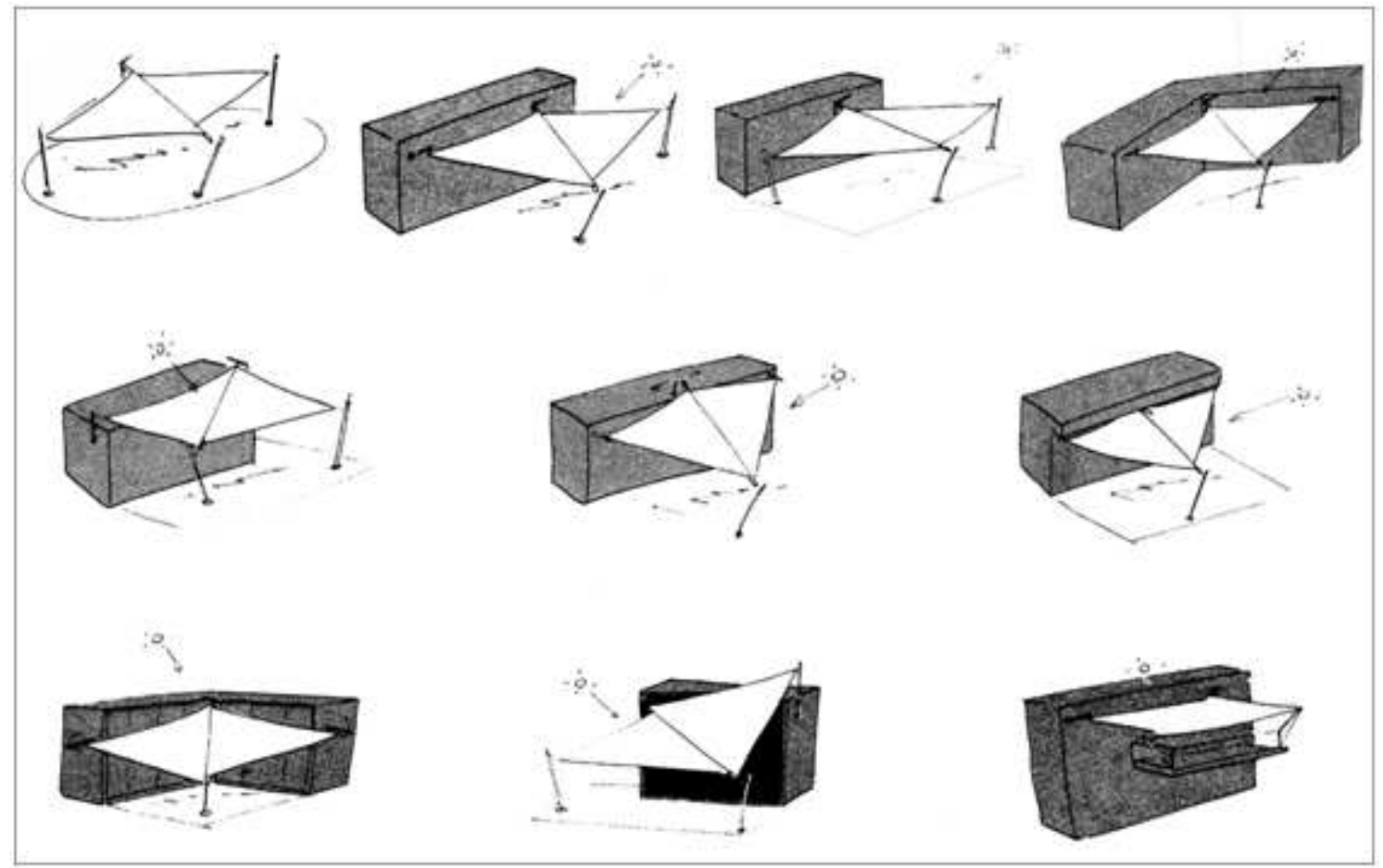

Figure 7: This System of Providing Outdoor Shelter using a Fabric Cover is a Practical, Flexible, and Functional Solution for Many Small- to Medium-sized Locations. Its Light, Airy Appearance, Even when Juxtaposed with Larger Surfaces, and its Ability to Practically Disappear at any Time, Makes it ideal for Outdoor Areas, which May be Subject to Either Sun or Shade. The Mobile Canopy is Operated by an Electric Motor Activated by a Wind Gauge and Light Meter (Bahamon., 2004, p. 96)

This shift, along with changes in material and related accessories may be better understood through an analysis of the literature and visuals available, and also by physical verification wherever possible, as per in Figure No.4, 5\&6. Illustrations in Figure No.7, showcase a group of temporary shelters and sunshades, made by using fabric in different positions, by Alejandro Bahamon. These canopy variations can be adapted to countless architectural situations, from openair to fully enclosed courtyards. Stainless steel anchoring and restraint cables are always outside the sails, to avoid encroaching on the covered surface. The sails' acrylic fabric resists wind, is very durable and strong, and comes in a wide variety of colours (Bahamon., 2004) The appearance of modern technology has seen further innovation, in the form and functions of the tent, making it lighter to carry and easier to install. Tour operators and camp managers carefully decide what kind of accommodation might suit the needs of their client and the topography of their site. For example, trekking and adventure camps involve the use of tents. Visuals in Figure No.8 were captured by the researcher at campsite near Jim Corbett national park, depicts the process of pitching and packing of a synthetic backpacker's tent, used as accommodation by campers and hikers.

\section{Craft of Tent Making}

As prehistoric man soldiered on, surviving against predators and inclement weather conditions, he chose or made his own shelter. It may be reasonably presumed that, he made his own temporary shelter too, including a tent. Of necessity, or by choice, in later years, pitching of a tent may have involved the entire family. In recorded history, of nomadic tribes, it is generally noted that, the men of the community pitched the tents and women decorated them. The fabric that draped the tent was woven and stitched by the women. Nomadic communities in various countries have been using tents and they are often the experts of this craft. 


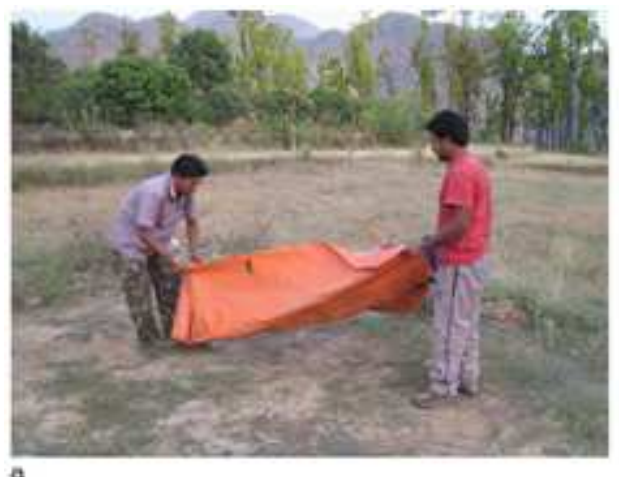

a
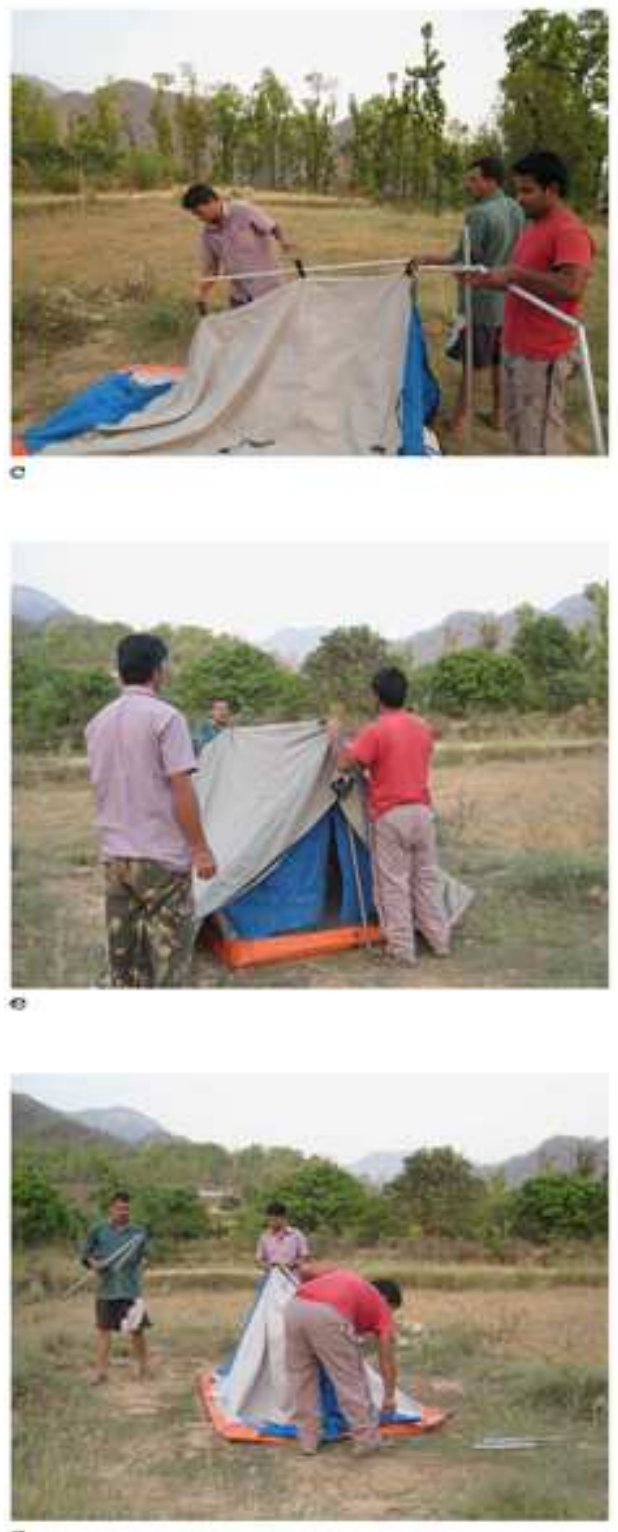
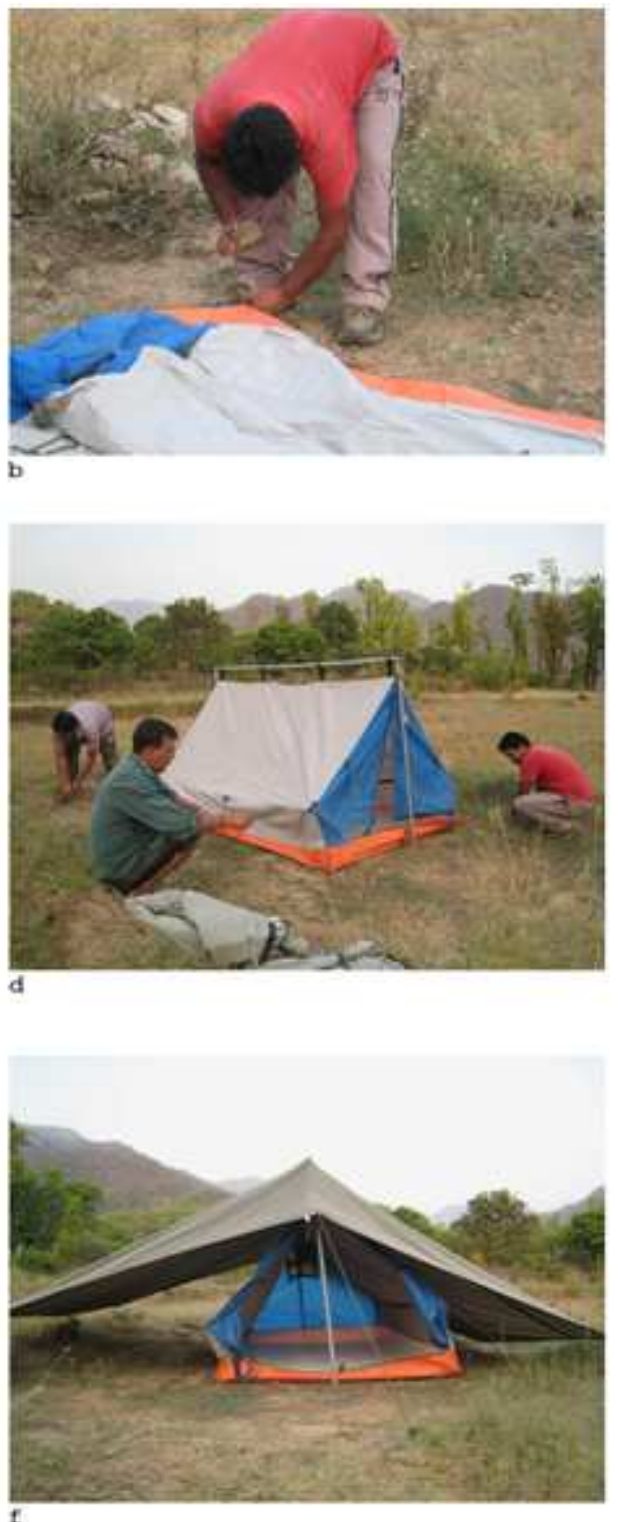

I

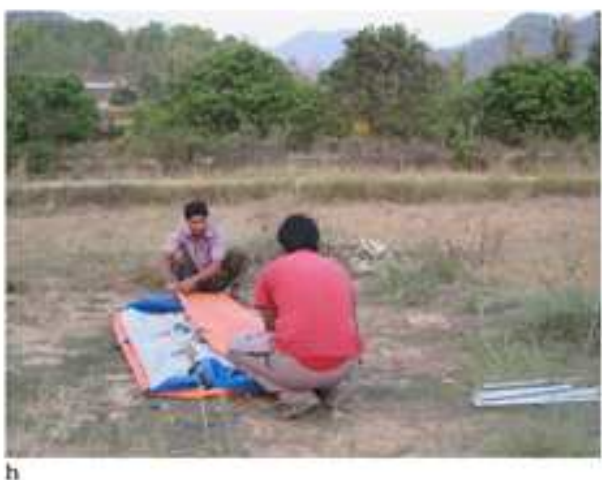

Figure 8: Process of Pitching a Camping Tent near Jim Corbett (Researcher's own)

In recorded history, of nomadic tribes, it is generally noted that the men of the community pitched the tents and women decorated them. The fabric that draped the tent was woven and stitched by the women. Nomadic communities in various countries have been using tents and they are often the experts of this craft. As described by Kahn, "and Arab tribes 
in North Africa, have developed several traditional shelter types, each responding to distinct local living patterns. These types could be characterised as stretched onto, dug into or built up"(Easton, 1973, p. 14).

“... They like to have richly decorated dwellings, and when a tent is made for a newly married couple, the women do their utmost to make the sheet very beautiful"(Easton, 1973, p. 12). Tent making flourished under the Mughal, Rajputana and British rulers in India. Mughal and Rajput craftsmen learnt from each other's skills and reinvented the tents for weddings, Durbars, hunting referred as Shikaar camps and safari expeditions. Even though produced professionally in special workshops, and for mass consumption, the tent has retained its identity of an indigenous craft till date. Whether produced by hand or machine, the tent is constantly improvised upon to accommodate various cultures and regions, and their functional demands. Though recorded reference of Rajasthani tent making is difficult to come by, AbulFazalAllami'sAai-ne-Akhbari, a historical literature has detailed descriptions of tents in the reign of the Great emperor Akbar, between years 1556-1605. A few tents were created for the royalty and were made to look like a palace, were also referred as royal tents. Experts erected these humongous double story tents, in less than a week. These tent structures were erected with the support of various pillars of different heights. Double storey tents were created with the help of wooden platforms to create a floor like structure. The queens of the royalty used the upper-floor of these tents as bedrooms or private rooms. Aai-ne-Akbari also has brief references about the tents used by hunters (Allami, 1873). As observed by the researcher through miniature paintings, similar traditions of tent making were followed over the centuries till $20^{\text {th }}$ century without many noticeable changes. Of the variety of tented structures, materials and forms constructed in the $20^{\text {th }}$ century, Dewaan-e-khaas is one of the most classic examples. Its versatility of design makes it relevant in the contemporary context as well. Dewaan-e-khaas iseight-sided octagonal shaped Indian tent with traditional accents and garden pavilions inspired by Indian Mughal architecture. These are specially designed for parties organised in the courtyards of large mansions. Erected without the centre pole, these tents created a rich ethnic feel of regal splendour (Gargtent). Tent roofs, the roofs of these tents were decorated beautifully on the outside with water repellent, off-white cotton canvas that had paisleys block print on them. Inside, the roof has a lining of maroon velvet enhanced with zardozi embroidery. Walls, the outer walls are decorated with floral designs, whereas the inside wall of tents are embellished with rich zardozi work panels, in different patterns. The frame, erected on an eight-sided pipe frame, these garden pavilions are connected with sockets, and therefore, it is possible for these to be pitched on hard ground as well as a soft base. Tents manufacturers, storage agencies and tenthouses mostly buy tents from auctions of the armed forces. Very often, these tents are not in useable condition and have to be repaired before being put to use. During tourist season, if there is an insufficient supply of tents, Shamiyanas or canopies are used. These canopies, which are mainly used in urban areas, are fit only as shelters and cannot be used as accommodation. The designs of these tents and canopies are out-dated. A face-lift is given to them by changing the fabric of the inner lining. Due to escalating prices and limited resources, these second hand tents are used as many times as possible. The tent-houses undertake the responsibility for transportation and installation of the tents. The equipment is transported to the site in hired trucks and the labour is sent along with them.

\section{Installation of Tent Encampments in Rajasthan}

No historic documents or references are available on the installation of tents, other than as mentioned in Aai-neAkbari, hence this section is largely based on personal observations during field visits. The present process of setting-up of tourist camps at suitable locations is a methodical task. First step is to make sure that the land is levelled, cleared of bushes and undergrowth, and then that it is fenced. Plumbing and drainage are the next concern. The water pipeline is laid 
connecting the catering and the toilet areas to the water source. The water source is usually a temporary water supply obtained from the local authorities. In areas where such supply is not available water tankers are brought and parked at the appropriate appointed spaces. A contract is given for the fitting of pipelines. The contractor charges on per foot basis. This rent includes labour for fitting the pipeline and other fittings such as taps. Once the camp is over the fittings are removed. It is not possible to make permanent connections as the sites themselves are not permanent and may be used for other activities like agriculture. A similar procedure is followed for the electrical fittings. After obtaining a connection from the electricity department, a contract is given. The charges to be paid are on per bulb basis, depending on the voltage of the bulb used or as per an agreement. After the water connections have been fitted and the indoor lighting completed, the pitching of tents and construction of toilets begin. The organisers may own their tents or take them on hire from agencies. These agencies hire out tents, Shamiyanas, furniture, crockery and cutlery. They are called tent houses and usually cater to urban functions and gatherings. In Rajasthan there are very few tent houses or suppliers. Shamiyana, this word has derived from Persian word Shamyanah, in English language, it is referred as Marquee or Awning. According to English dictionary Merriam Webster, Shamiyana means, a cloth canopy (Webster, Janaury 1994).

\section{Materials for the supportive structure}

Wood used to be the most popular material, as it was easily available and could weather extreme climatic conditions for a reasonable period of time. It is still the preferred material but due to finite reserves is extremely expensive to procure. The skills, equipment and facilities required for handling wood are simpler than those of metal but wood succumbs to wear and tear during use, transportation and storage. It is food for insects and requires regular maintenance even though its products can be repaired and replaced easily. Cane and bamboo are lightweight, malleable materials that do not have a long life. Synthetic materials, such as nylon, polyester and polyvinyl are strong and lightweight materials. Nylon and Polyester are used as ropes and for stitching, whereas PVC pipes are used for plumbing and drainage. They are noncorrosive and not affected by water. They are easy to mould. There is a of lot scope for exploring suitable forms for members and joinery of tents using these synthetics. Though the cost of the material is not very high, replacement and customised fabrication could turn out to be expensive. None of the above-mentioned materials are fire resistant or fire retardant. Among metals, aluminium is lightweight and has a very good strength-weight ratio. Being non-corrosive it is suitable for outdoor use. But it involves a complex welding process, which is not readily available. The cost compared to mild steel is very high. Mild steel rod, rods made of mild steel are easy to bend and can be joined by simple welding due to their small diameters. However joinery, allowing flexibility of movement, is only possible with the introduction of additional material. The mild steel rods have a poor strength-weight ratio, and long spans of the rod tend to sag under their own weight. Mild steel pipe, pipes have a much better strength weight ratio than rods; so they are lighter and stronger. Due to the larger diameter there is sufficient space for joinery details. Cold bending is possible and is the usual method of bending pipes. Mild steel pipes are cheaper than the mild steel rods. Although mild steel is not non-corrosive, it can be covered with a protective layer of paint.

\section{Material for Covering}

Nylon, this synthetic material is very light and waterproof. Although it is a very tough material, once damaged it is very difficult to repair. Nylon is highly inflammable and not suitable for hot climates. The cost of nylon is much higher compared to that of canvas. Leather is a very tough material and can stand a lot of wear and tear. It is water resistant to a point but not water proof, and can get damaged with constant wetting. Unlike synthetic materials, it is available in irregular 
lengths instead of in long continuous strips, which are necessary for covering large surfaces. Canvas, is cotton material available in various thicknesses and can be finished to achieve a degree of waterproofing. Canvas itself is water resistant to a certain extent. Earlier, few waxed cotton fabrics were traced back in the $16^{\text {th }}$ century, where waterproofing was done using oil, grease and beeswax. In the $19^{\text {th }}$ century, a wax made of paraffin (a substance derived petroleum refining process) was used on canvas for water proofing as an alternate to beeswax, it continued till mid 1950s. However, this waterproofing was not very practical as the canvas cracked along its fold, when folded for packing. In the new method of waterproofing, the canvas is laminated on one or both sides with a chemical referred as Polyvinyl Chloride (PVC). If so desired, PVC colour is also added to the canvas. The PVC laminate makes the canvas waterproof and airtight (New online: Barbour Wax Thornproof Dressing, 2009).

\section{Storage of Tents}

For portability and storage of tents, it is practical to make them stackable, foldable or knockdown. Stacking is piling up one piece on top of or against another. It is a good way of storing products that have simple shapes and are lightweight. Stacking works best with products that are single pieces, without any loose or irregular appendages. It saves time and space, compared to other ways of storing. It may prove to be unsuitable for large sized products, as they occupy much more space than the actual volume of the material. In case, if large sized products are stacked, then the increased bulk of the pile becomes unbalanced and hazardous. Folding is the doubling over of a product to reduce its length or bulk or both. This method is suitable for soft and malleable products of any size and shape. Material can be folded and stacked for better management of space. However, this is a time consuming method. Also, those portions that are creased during the folding tend to get distressed and damaged. If the material be even a little bit hard, the fabric would break at the folded edges. In the knockdown system, the product is modular and made such that, the different parts may be assembled or taken apart easily. This allows large products to be reduced to smaller sizes, so as to facilitate their stacking or storage. As the knockdown system will have many loose parts, the assembly and dismantling may take much more time as compared to other methods and also result in loss of smaller parts. Thus, a system needs to be evolved which can have the advantages of all the three methods, for enabling easy mobility and efficient storage of tents in large numbers. It would be ideal to divide the product into identical units, which may be assembled or dismantled as per the knock down system. After the units are separated, fabric may be folded and stacked along with the supporting members.

\section{Pitching of Tent}

In India, Shamiyana is a most commonly used outdoor ceremonial tent shelter or awning, used for private and public events, such as, marriages, parties, exhibitions, trade-shows and political or other promotional events etc. A Shamiyana is usually in a square or rectangular shape, the four corners are supported with wooden or metal poles, the roof is stretched out with ropes over these poles and ties to wooden or metal pegs on the ground. A Shamiyana is ready for use after placing removable flexible sidewalls on desired sides. The process of pitching tents on a campsite or for a ceremony involves, unloading all the Shamiyanas and spread them out on the ground, adjacent to each other. The Shamiyanas are joined to each other by means of a rope, which passes through the loops on the edges of the Shamiyanas. Once this is over, the large canopy or the Shamiyana roof is raised on poles, row by row, one canopy at a time. Innumerable poles hold up this canopy, one on every corner of the individual Shamiyana. After this, the sidewalls also referred as Kanaats are put up, subdividing the space beneath and enclosing it. If required, simultaneously, the catering area is set up in the central part of the campsite by joining a number of small Shamiyanas. This area is for dinning, refreshment and the kitchen. Compared to 
the residential area, this is a larger covered area with a proper exit and enclosure. Based on the requirement, purpose and usage of tents, different variation in layouts, sizes and shapes are adopted while pitching of tents; this leads to creating various types of tents. The accommodation at the camp is broken up into different units. Since at present, the RTDC are using various types of tents, the units are based on the type of tents. Each large tented unit being used as a dormitory has its own store, laundry and toilet. Smaller tented units are provided with two chairs and two beds each, complete with mattresses, pillows, bed sheets and blankets (RTDC, 2009). The pitching of the residential tents is a very precise and coordinated task. The tents that have been unloaded at a convenient spot are then placed at their individual locations. The two layers of the roof are spread out, one on top of the other. The central pole is then slid beneath the roof and hoisted along with the roof. Once this is done, the ropes at the four corners of the roof layers are pulled, thus stretching the canvas of the roof. After the layers of the roof have been stretched to their fullest, the ropes are tied to the pegs staked to the ground. The tying has to be done very carefully so as to maintain the gap between the outer and the inner layer of the roof. This gap is very important for insulation and ventilation. After the roof is fixed, the sidewalls, that are canvas reinforced with bamboo, are pushed beneath the edges of the roof. Sidewalls stay in position by having the bottom ends buried in the ground and the top ones tied to the edges of the roof. These tents have a square floor area. This regularises the size of the supporting poles and allows the tent to be oriented in any direction without changing its layout or its perimeter. This is an advantage when the space available is less. A rectangular floor space is possible but would compromise on freedom of orientation. During various field visits, the researcher noted a most common thing, that almost all the tents have a floor area of 4 metres $x 4$ metres per tent approximately. It is meant for two people and is provided with two beds and two chairs and there is space for a third bed. There is also a locking facility on the door. In normal, cuboid, spaces the corners on the ceiling are not of any use, thus they are eliminated in the tents by the truncation. Due to this truncation, the surfaces of the form have been broken up into triangles, which make it structurally very stable and usable. The truncation also helps in reducing the wind resistance. As the areas perpendicular to the ground have been reduced, and slanted areas increased, the air circulation is made much smoother. Swiss cottage tent is another popular type of tent used by tourism industry in Rajasthan and in many other parts of India. These are usually the tents that accommodate a double bed and have an attached toilet. They have a provision for one extra bed. Each tent is supported by one central pole. From this pole, the roof is stretched out by ropes and tied to pegs, and then the sidewalls are rolled out around it. These walls are reinforced with bamboo poles that are buried in the ground. The toilet facilities for the tented accommodation are a semi-permanent system. The septic tanks and the roofing are permanent. The walls and partitions are made of sheet metal and fabricated together with a rod of slotted iron angles. The tents around a campsite are placed such that the WCs within the toilet of two or three tents are easily connected to a common septic tank. The water pipes are laid underground and water storage tanks are mounted on wooden structures. Another popular tent used in present day is referred as Octahedron tent by most local tent manufacturers, this canvas tent has derived from the cube-octahedron solid form, which itself is derived by truncating a cube, and an octahedron.

\section{Observation}

One of the most appropriate canvases recommended for use in Octahedron tent is available in $150 \mathrm{~cm}$ width. Though the widths required for the tent is much more, to accommodate this width, each side of the tent will have to be made of two widths of canvas. The joint where the two widths of canvas will be stitched together will be stiffer and stronger than the canvas itself. This can be used to add to the structural rigidity of the tent. After trying various alternatives, 
the ideal solution seems to be to divide each rectangle into two, half way from the base to its apex, diagonally. When the tent is assembled, each of these stitching lines will run across the surface of the tent diagonally, thus making the canvas walls stiffer and sturdier. As the form of the tent can tessellate with multiples of its own, large covered areas can be created. Pitching the tents adjacent to each other and removing the sidewalls between them can achieve larger covered areas. Such areas can be used as reception halls, for catering, dining areas, and dormitories. A few important things those could be considered and kept in mind when deciding to set a tent are, such as, selection and layout of location/site in respect to topography, weather, direction of wind, vegetation, natural resources, storage, connectivity and approach from the main road, portability and mobility.

\section{ANALYSIS AND DISCUSSIONS}

The canvas tent has been used for centuries together. These tents are available in a variety of sizes. Starting from the one meant for single accommodation to one that would fit a family of four. The pitching of tents is not as simple as it appears to be. Below are discussed some of the problem areas one faces when pitching a cotton canvas tent.

- The designs of the cotton tents in use are out dated due to lack of design initiatives in this field. These traditional tent designs have suffered due to the escalating cost of material and skilled workmanship. Compromises in the quality of material used, and workmanship, have undermined the form and function of a tent.

- The commonly used canvas tent is not a self-supporting structure, a lot of time and energy is spent in stretching and tying the structure. The tying has to be done with great care and skill so as to maintain the gap between the two layers of the roof.

- .This gap is necessary for insulation. The gap is created by tying the inner layer of the roof to the pegs closer to the tent and the outer layer of the roof to the pegs away from the tent. Very often this is not done. Ropes of both the layers are tied to the same peg, consequently there is no insulating gap formed between the two layers.

- The hoisting and tying of the roof requires a minimum manpower of five people, simultaneously. With one person holding the central pole, four more are needed to stretch the corners of the roof.

- The ropes, which are stretched out and tied to the pegs, occupy a lot of space. This space goes unused and thus is a waste.

- The central pole is a very divisive element. It hinders movement and limits the possibility of various layouts of furniture. Visually too, it is very disturbing.

- The sandy soil of Rajasthan also poses a lot of problems. In strong winds, there is a constant problem of sand blowing into the tents. This has to be overcome by constantly spraying the ground with water.

- The pegs take all the load of the tents and thus have to be very firmly buried into the ground. Sandy ground conditions, in parts of Rajasthan, do not provide sufficient grip to the pegs. Even if the pegs are dug in very deep there is always the danger of the pegs giving way.

- Very often the furniture, when in use, tends to sink into the sand, causing a lot of inconvenience.

In peak tourist season, if there is not a sufficient supply of tents available, Shamiyanas are used. These Shamiyanas come with their own set of shortcomings. First, the Shamiyana is only a large roof that requires partitions, 
sidewalls and doorways to be constructed out of local available material. Residential spaces thus created are unfinished and lack sufficient privacy. Second, the Shamiyanas are not self-supporting structures. They too need a lot of time and labour to be pitched. Then last, the placements of supporting poles of a Shamiyana disrupt and divide the usage of space beneath the canopy. The newer tents are made of waterproof synthetic material and can be easily blown up using an air pump. While the newer tents are easy to put up, they take longer to be flattened out. They can also be easily blown away in case of high winds. So if you sleep with a synthetic tent roof over your head, the possibility is that you may wake up the next morning with the sky as your roof. Synthetic materials like nylons, polyesters and plastics are very strong, but once damaged, they are extremely difficult to repair. To sum-up, some of the major concerns in offering tented accommodation facilities in Rajasthan are; the rocky and sandy terrain, the time and labour required in pitching a tent, the pegs take all the load and tension of the tents, but their grip in the sand is precarious. Also the area occupied by the tents is much greater than the area actually used, the space inside is not ideal as poles that support the tents break the space up and the canvas tents tend to tear at the places where the ropes are joined to it. The provisions for ventilation and insulation in tents are not sufficient, the furniture tends to sink into sandy soil or topple over on rocky grounds. As mentioned earlier the contemporary lightweight tents are in the danger of being blown away by Rajasthan's high velocity winds. Hence all these concerns need to be addressed while provide.

\section{CONCLUSIONS}

Tent has been a transcendental product, catering to various needs with changing times. Even though with its roots lying deep in history, it is still relevant and forms the basis of a thriving business of sheltering tourists in Rajasthan and in adventure camps, along with its other multitude of applications. With an in depth study of the various components like pitching of the tent, the types of materials used for making the roof, support structure, side walls, entry, storage of the tents etc., certain concerns have been pointed out regarding canvas tents. These can enable the concerned stakeholders to identify, as well as solve the issues in the future. Guidelines for selecting a campsite provide vital information for future endeavours. Tents play an important role in our lives, not only do they have heritage value, they also are far from being redundant with the vital role they play as temporary shelters even today. Tents are a testimony of progress and innovation, absorbing and adapting to each and every change, with the passage of time.

\section{REFERENCES}

1. Akbar, S. (1997). Mughal Tent Project London. London, U.K.: V \& A Museum.

2. Allami, A. F. (1873). The Ain-I-Akbari (1590). (H. Blochmann, Trans.) Calcutta, Inida: G. M. Rouse Publication.

3. Armijos., S. J. (2008). Fabric Architecture: Creative Resources for Shade, Signage, and Shelter. New York: W.W.Norton \& Co.

4. Bahamon., A. (2004). The Magic of Tents: Transforming Space. New York: HarperCollins.

5. Bally, C. A. (1991). An Illustrated History of Modern India 1600 - 1947. Bombay: Oxford Univ. Publication.

6. Bhati, S. S. (Ed.). (2007). Dera Ro Khato. Jodhpur, Rajasthan, India: Maharaja Mansingh Pustak Prakash Recearch Centre, Fort, Jodhpur.

7. Drew, P. (2008). New Tent Architecture. New York: Thames \& Hudson.

8. Easton, L. K. (Ed.). (1973). Shelter. California: Shelter Publication Inc. 
9. Gargtent. (n.d.). Garg Tent. Retrieved August 9, 2012, from Gargtent.com.

10. History of India. (2011, December 5). Trade and Transportation. Retrieved December 21, 2012, from Wikipedia.

11. IGNCA and INTAC. (2010). Delhi A Living Heritage. New Delhi, India: IGNCA.

12. Jain, R. (2009). Durbar Royal Textiles of Jodhpur. Jodhpur: Mehrangarh Museum Trust.

13. Jodhana Heritage Resorts. (2012). Royal Jodhpur Retreat and Camps. Retrieved April 14, 2012, from jodhanaheritage.com.

14. New online: Barbour Wax Thornproof Dressing. (2009, November 05). lark-blogvancouver.blogspot.in. Retrieved March 11, 2017, from lark-blogvancouver.blogspt.in/2009/11/new-online-borbour-wax-thornproof.html

15. RTDC. (2009). Rajasthan Tourism Development Corporation. Retrieved February 21, 2010, from RTDC: rtdc.in

16. Seth, M. (2006). Indian Painting - The Great Mural Tradition. India: Mapin Publication.

17. Valmiki Ramayan. (2003, May). Ayodhya Kanda in Prose - Sarga 80. (K. M. Murthy, Editor) Retrieved April 19, 2013, from Valmikiramayan.net.

18. Webster. (Janaury 1994). Webster's New Encyclopedia Dictionary. New York: Black Dog \& Leventhal Publication. 

